\title{
Smart Integrated Sensor for Multiple Detections of Glucose and L-Lactate Using On-Chip Electrochemical System
}

\author{
Tomoyuki Yamazaki, ${ }^{1,2}$ Takaaki Ikeda, ${ }^{1}$ Byounghyun Lim, ${ }^{1}$ Koichi Okumura, ${ }^{1}$ \\ Makoto Ishida, ${ }^{1,3}$ and Kazuaki Sawada ${ }^{1,3}$ \\ ${ }^{1}$ Department of Electronic and Information Engineering, Toyohashi University of Technology, C3-601, 1-1 Hibarigaoka, Tenpaku, \\ Toyohashi, Aichi, 441-8580, Japan \\ ${ }^{2}$ New Product Development Department, Hioki E. E. Corporation, 81 Koizumi, Ueda, Nagano 386-1192, Japan \\ ${ }^{3}$ JST-CREST, Sanban-cho Building, 4F, 5 Sanban-cho, Chiyoda-ku, Tokyo 102-0075, Japan
}

Correspondence should be addressed to Tomoyuki Yamazaki, yamazaki-t@int.ee.tut.ac.jp

Received 14 February 2011; Accepted 26 April 2011

Academic Editor: Michele Penza

Copyright (๑) 2011 Tomoyuki Yamazaki et al. This is an open access article distributed under the Creative Commons Attribution License, which permits unrestricted use, distribution, and reproduction in any medium, provided the original work is properly cited.

Multiple sensor electrodes, a supplementary electrode, a reference electrode, and signal-processing circuits were integrated on a single chip to develop a chip-shaped electrochemical sensing system. L-lactate and glucose were measured using on-chip working electrodes modified by polyion complex to immobilize lactate oxidase and glucose oxidase, respectively. Cyclic voltammetry measurements were conducted using an on-chip potentiostat. Selective and quantitative detection of glucose and L-lactate and the interference behavior were studied. Hydrogen peroxide generated by enzymatic reactions was detected by an increase in anodic oxidation current. Reaction currents at $+0.7 \mathrm{~V}$ versus $\mathrm{Ag} / \mathrm{AgCl}$ were used to obtain calibration plots. The measured dynamic ranges for L-lactate and glucose were $0.2-1.0 \mathrm{mM}$ and $2.0-8.0 \mathrm{mM}$, respectively. The sensitivities were $65 \mathrm{nA} / \mathrm{mM}$ and $15 \mathrm{nA} / \mathrm{mM}$, respectively, using a working electrode of $0.5 \mathrm{~mm}^{2}$. The $3 \sigma$ detection limit was $0.19 \mathrm{mM}$ and $1.1 \mathrm{mM}$, respectively. We have achieved multiple biomaterial detections on a circuit-equipped single chip. This integrated electrochemical sensor chip could be the best candidate for realizing point-of-care testing due to its portability and potential for mass production.

\section{Introduction}

Electrochemical sensors have attracted attention in recent decades because they have been used in clinical inspection, environmental assessment, and battery technology. Generally, biosensors need fewer chemicals and a smaller sample volume and require few pretreatments. In addition, because of their selectivity and sensitivity, biosensors are of great importance for future health checkups. Many studies have examined clinical diagnosis, including detection of L-lactate [1-4], detection of glucose [5-7], and detection of other biomaterials or combinations of biomaterials [8-10].

Some reports on miniaturizing the entire sensing system have appeared recently [11]. With rising demands for personal care, portable, reliable, and fast biosensors are desired. Bulky electrochemical instruments should be miniaturized for future on-site measurement applications. To fulfill these requirements, electrochemical sensors using complementary metal-oxide semiconductor (CMOS) circuits could be the best candidate [12-15]. The entire system can be integrated into a single chip using a standard CMOS technique and a few electrode fabrication processes, which is promising because of the potential for mass production. Our objective is to fabricate a compact intelligent sensor chip to realize a portable and reliable sensing system that combines CMOS technology and electrochemical sensors.

Electrochemical sensors with CMOS circuits were reported recently. Levine et al. incorporated CMOS circuits into an electrochemical sensor [16] to detect DNA hybridization. Our group also demonstrated a CMOS-integrated electrochemical sensor [17]. However, an external reference electrode (RE) was used in both cases. To respond to the demand 
for a compact electrochemical measurement system suitable for point-of-care testing, a more integrated sensing system is needed.

In this paper, we have successfully developed an electrochemical sensing system that integrates multiple working electrodes (WEs), a counter electrode (CE), an RE, and signal-processing circuits. To the best of our knowledge, this is the first electrochemical sensing chip in which those components required for electrochemical measurements are integrated. One future application of the chip is point-ofcare testing: quick, simple checkups at patients' bedside. Llactate and glucose were chosen as example materials to demonstrate the future application of this biosensor chip.

\section{Device Fabrication}

The device was designed and fabricated at the Toyohashi University of Technology (Toyohashi Tech) using CMOS $5.0 \mu \mathrm{m}$ technology. The fabrication process began with an ntype silicon wafer. First, CMOS circuits were fabricated on the wafer in a clean room by oxidation, ion implantation, and photolithography. Then a platinum layer was sputtered, followed by titanium sputtering, using RF sputtering equipment. The titanium layer was used as an adhesive layer. The titanium and platinum layers were $0.05 \mu \mathrm{m}$ and $0.2 \mu \mathrm{m}$ thick, respectively. Electrodes were patterned using a lift-off method. Finally, all the chip surfaces except the electrodes were covered with a parylene layer to protect the circuits and wiring patterns from the solution under investigation.

A diced $5.0 \mathrm{~mm}$ square chip is shown in Figure 1, and a cross-sectional image of the chip is shown in Figure 2. There are four WEs, a CE, and an RE. Each WE is $710 \mu \mathrm{m}$ square. In this study, two WEs were used. Operational amplifiers (OPAMPs) are aligned along the right side and the bottom side of the chip. All OPAMP terminals were connected to pads so that these OPAMPs could be interlinked by wiring to make a potentiostat. Chip fabrication took 82 operations in total, and 12 masks were used.

The chip was fixed in an 80-pin package using silver paste. The pads and package were connected through $20-\mu \mathrm{m}-$ diameter gold wires. The wires were encapsulated with silicone adhesive (MPMJ TSE387-W) to avoid unwanted contacts and create a sample well of about $70 \mu \mathrm{L}$. The surface of the chip was cleaned [18] using piranha solution $\left(\mathrm{H}_{2} \mathrm{SO}_{4}: \mathrm{H}_{2} \mathrm{O}_{2}=3: 1\right)$, and electrochemical cleaning of potential $-3.0 \mathrm{~V}$ was applied to each electrode against an external platinum electrode for $30 \mathrm{~s}$. Then, $\mathrm{Ag} / \mathrm{AgCl}$ ink (BAS 011464) was dropped manually by a needle on the RE position and dried $\left(100^{\circ} \mathrm{C}, 1 \mathrm{~h}\right)$ to form an RE. Finally, WEs were modified with enzymes. The package and chip with sample solution are shown in Figure 3.

\section{Experimental}

3.1. Chemical Reagents. All solutions were prepared using analytical reagent grade chemicals and MilliQ water. Lactate oxidase (LOD, EC 232-841-6, $42.8 \mathrm{U} \mathrm{mg}^{-1}$ ) from the

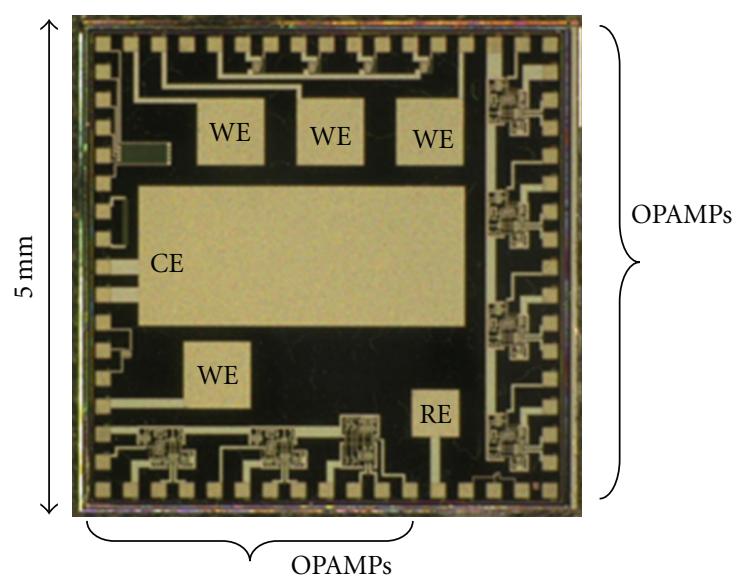

FIgure 1: Top view of fabricated chip. Working electrodes (WEs), counter electrode (CE), reference electrode (RE), and operational amplifiers (OPAMPs) are integrated.

Pediococcus species, glucose oxidase (GOD, EC 232-601-0, 153.1 $\mathrm{U} \mathrm{mg}^{-1}$ ) from Aspergillus niger, and poly-L-lysine hydrobromide (molecular weight $\leq 150,000$ ) were purchased from Sigma. Poly(sodium 4-styrenesulfonate) (molecular weight $\sim 70,000)$ was purchased from Aldrich. Lithium Llactate was purchased from Fluka, and $\mathrm{D}(+)$-glucose was obtained from Kishida Chemical.

3.2. Enzyme Immobilization on Electrodes. First, the surfaces of the WEs were cleaned electrochemically. In the process of cleaning, a potential of $-3.0 \mathrm{~V}$ was applied to each electrode for $30 \mathrm{~s}$ versus an external platinum electrode using an electrochemical analyzer (BAS CV-50 W). Surface cleanliness was confirmed by taking the cyclic voltammetry (CV) of $10.0 \mathrm{mM} \mathrm{K}_{3}\left[\mathrm{Fe}(\mathrm{CN})_{6}\right] / 0.1 \mathrm{M}$ phosphate buffer solution (PB, $\left.\mathrm{Na}_{2} \mathrm{HPO}_{4}: \mathrm{NaH}_{2} \mathrm{PO}_{4}=1: 1, \mathrm{pH}=6.58\right)$ with an external RE (BAS, RE-1B). Judging from obtained clear peaks of $\mathrm{K}_{3}\left[\mathrm{Fe}(\mathrm{CN})_{6}\right]$ (not shown), unfavorable contamination and an oxidized layer on the electrode surface were considered to be removed by cleaning.

Enzymes were immobilized using the polyion complex method [19-21]. Each chemical reagent was dissolved in $0.1 \mathrm{M} \mathrm{PB}$. First, $0.7 \mu \mathrm{L}$ of $0.1 \mathrm{mM}$ poly(sodium 4 -styrenesulfonate) was dropped onto the electrodes. Then $0.7 \mu \mathrm{L}$ of LOD solution $\left(50 \mathrm{U} \mathrm{mL}^{-1}\right)$ or $0.7 \mu \mathrm{L}$ of GOD solution $\left(4.0 \mathrm{mg} \mathrm{mL}^{-1}\right.$ ) was dropped onto the electrode continuously. Finally, $0.7 \mu \mathrm{L}$ of $0.05 \mathrm{mM}$ poly-L-lysine hydrobromide was dropped. The solution was dried at room temperature for $12 \mathrm{~h}$ to immobilize the polyion compound on the electrode. When it was not in use, the chip was stored at $-4^{\circ} \mathrm{C}$ in a refrigerator with a droplet of $\mathrm{PB}$ on it. Polyion complex layers are stable for about a month [20]. Generally speaking, a measurement system with LOD and a sensing electrode system can be affected by electrochemical interference substances including L-ascorbic acid and uric acid. But by filtering them with polyion layer, such interferences could be avoided [20]. 


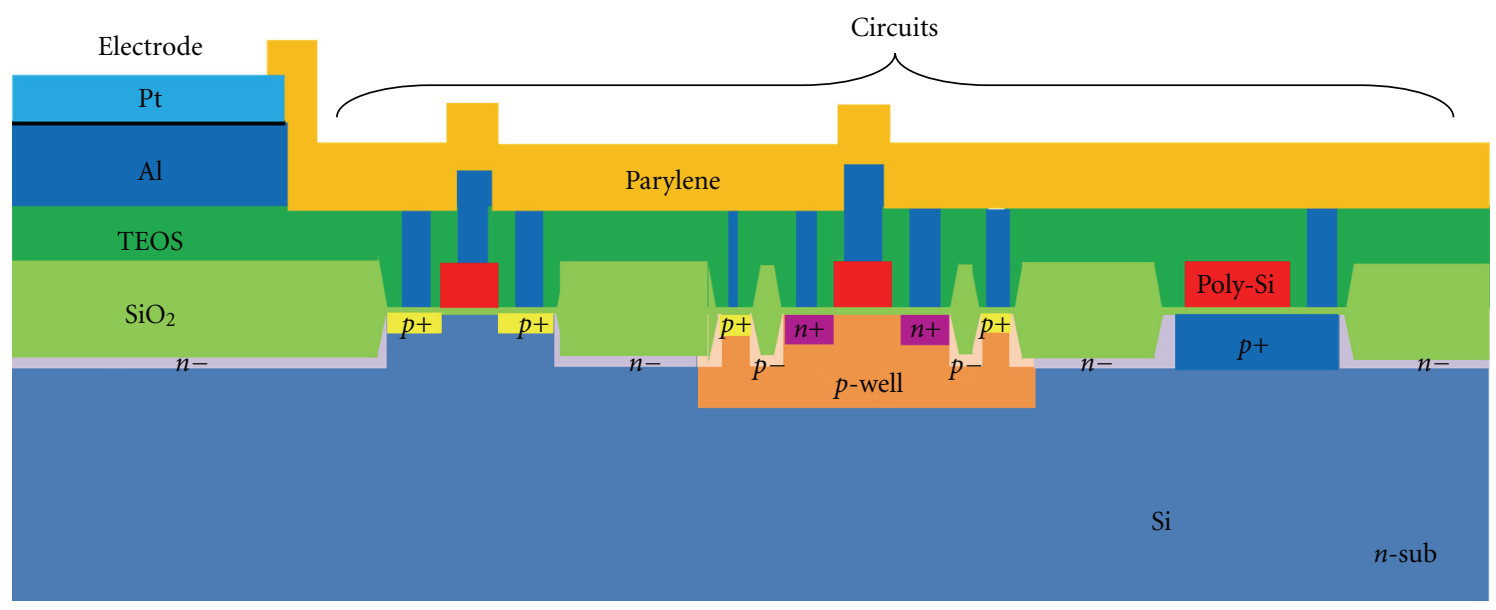

FIgURE 2: Cross-sectional image of the sensor chip. TEOS means tetraethoxysilane.

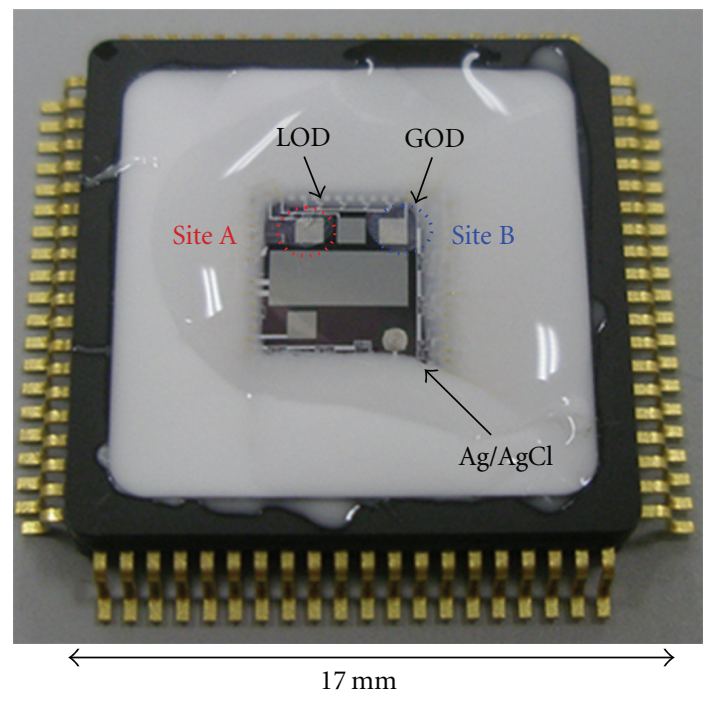

FIgURE 3: Top view of the packaged chip.

\section{Results and Discussion}

4.1. Cyclic Voltammetry Using On-Chip Circuits. A schematic of the potentiostat, which consisted of two OPAMPs, is shown in Figure 4. The equivalent circuit of the designed two-stage OPAMP is shown in Figure 5. The phase-compensation capacitance was designed to be $3.0 \mathrm{pF}$ to drive a capacitive load of a few $\mathrm{pF}$. The drive voltages of the OPAMPs were $V_{\mathrm{dd}}=+2.5 \mathrm{~V}$ and $V_{\mathrm{ss}}=-2.5 \mathrm{~V}$. The consumption current of the potentiostat during the measurement was $0.17 \mathrm{~mA}$. All components except the readout resistance were included on the chip to avoid fluctuation in the resistance caused by heat from the OPAMPs.

The details of this type of potentiostat are explained in the previous report [17]. Briefly, the input voltage $\left(V_{1}\right)$ was applied and swept from $V_{\mathrm{s}}$ to $V_{\mathrm{e}}$ and then back to $V_{\mathrm{s}}$. The potential between the RE and the WE was controlled by maintaining the potential of the WE at ground level and making the potential of the RE follow $V_{1}$. The CE works as

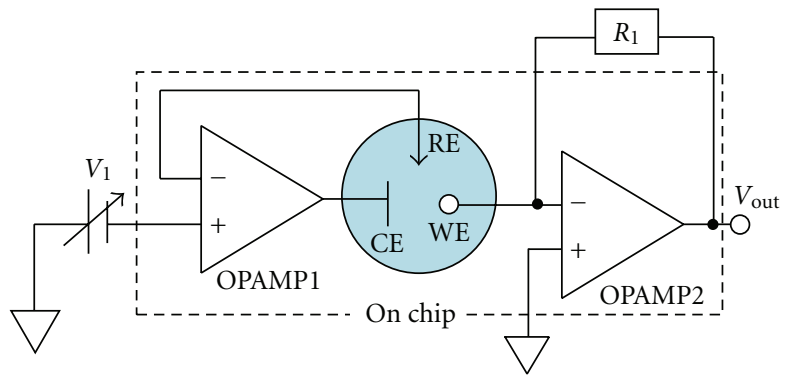

Figure 4: Schematic of electrochemical measurement system: potentiostat and electrodes.

a current source or sink. The reaction current at the WE was converted to voltage at OPAMP2, which was read out as $V_{\text {out }}$.

4.2. Selective Detection of L-Lactate and Glucose. L-lactate and glucose solutions were prepared by dissolution with $0.01 \mathrm{M} \mathrm{PB}$ solution and $0.9 \mathrm{wt} \%$ saline solution (PBS). LOD was immobilized on the leftmost WE (site A), and GOD was immobilized on the rightmost WE (site B), as shown in Figure 3. The solution of $70 \mu \mathrm{L}$ was dropped on the chip using a micropipette. With $0.5 \mathrm{mM}$ L-lactate, a clear current increase was observed at site $\mathrm{A}$, but the current appeared stable at site B, whereas with $5.0 \mathrm{mM}$ glucose, a clear current increase was obtained at site $\mathrm{B}$, but the signal was stable at site A. The CV results described above are shown in Figure 6. The mechanisms of L-lactate and glucose detection are shown in Figure 7. Both L-lactate and glucose were oxidized by the corresponding enzymes, LOD and GOD, and hydrogen peroxide $\left(\mathrm{H}_{2} \mathrm{O}_{2}\right)$ was generated. Since the enzymes were immobilized to the WE through a polyion complex, hydrogen peroxide was generated only near the WE. Consequently, when LOD was active, only site A was active, and vice versa.

Because both sites detect hydrogen peroxide, interference should be considered quantitatively. The crosstalk behavior was investigated by measuring the temporal behavior of the CV curve at site A after $10.0 \mathrm{mM}$ of glucose solution was 


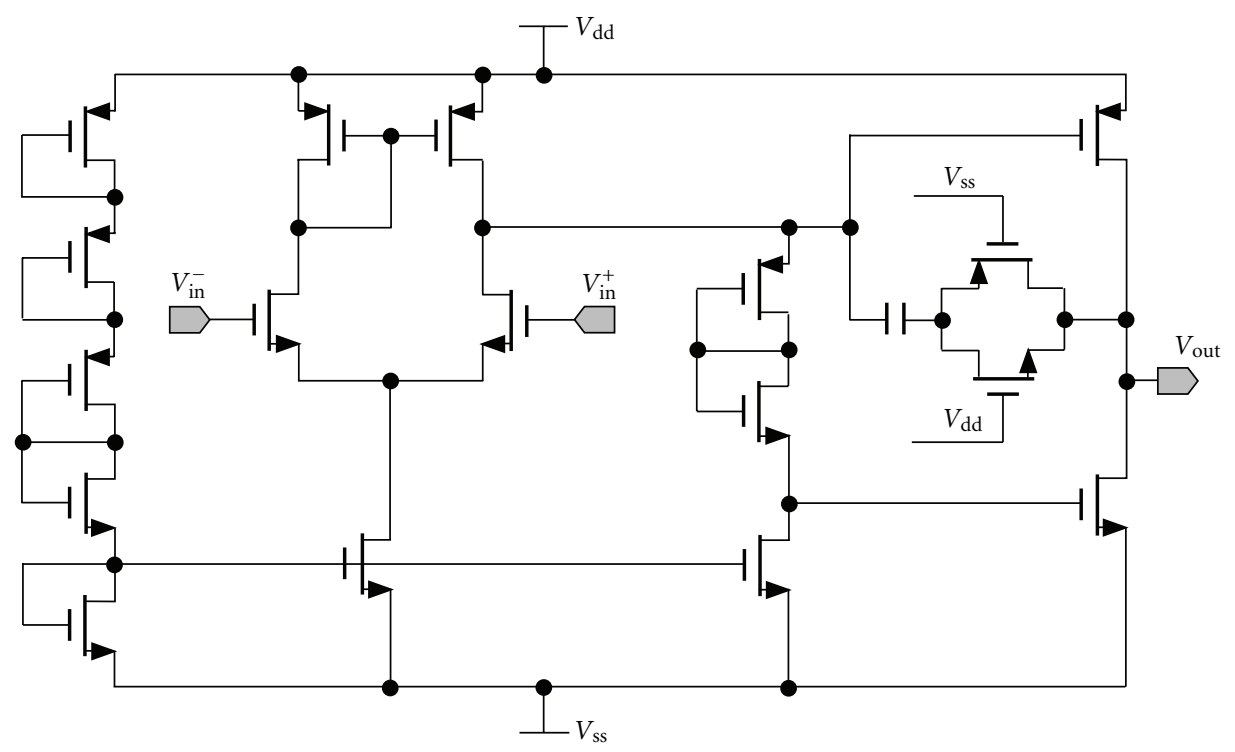

FIgURE 5: Equivalent circuit of designed operational amplifier.

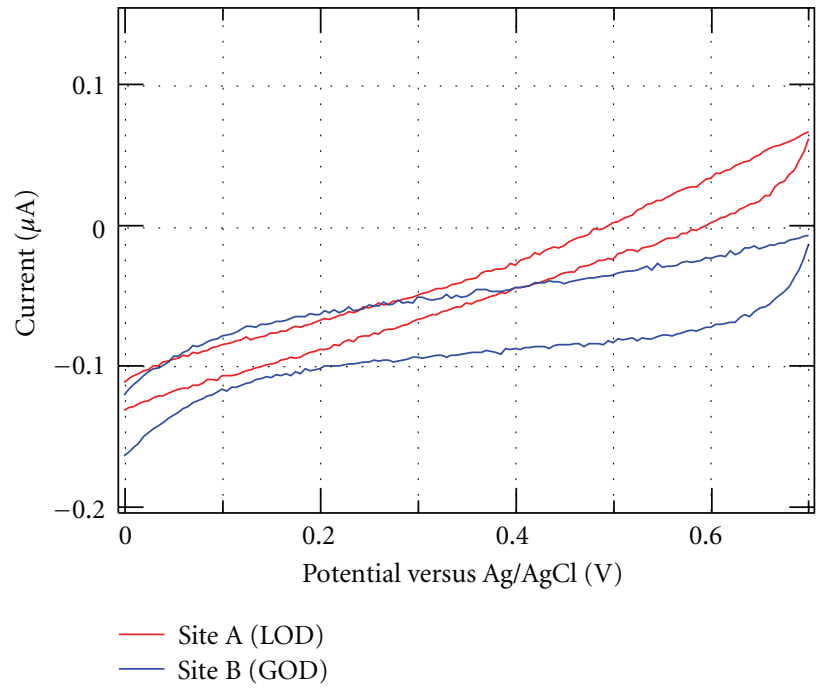

(a)

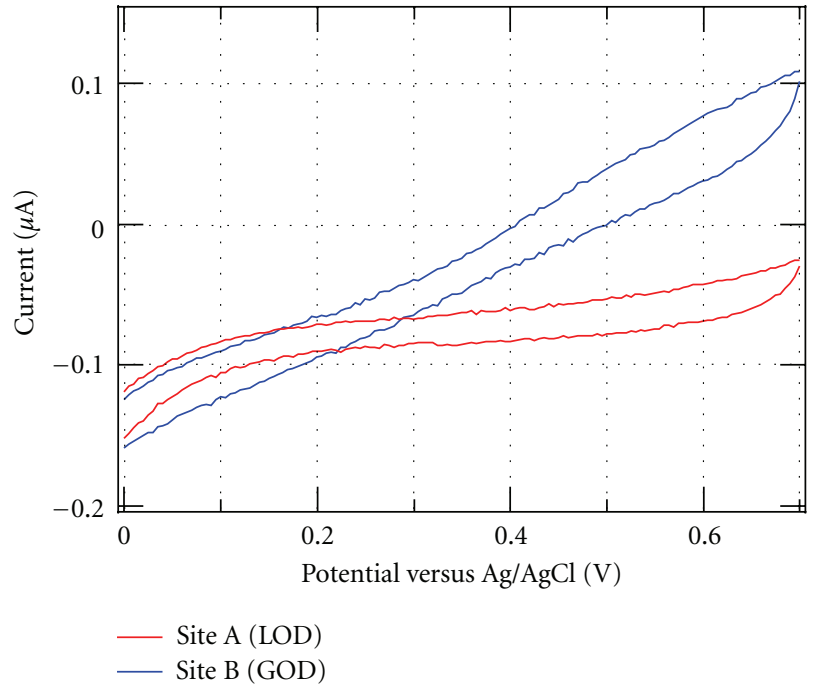

(b)

FIGURE 6: Difference in cyclic voltammetry curves between site A (lactate oxidase (LOD) was immobilized on working electrode) and site B (glucose-oxidase (GOD) was immobilized on working electrode) measuring (a) $0.5 \mathrm{mM}$ L-lactate solution and (b) $5.0 \mathrm{mM}$ glucose solution. Scan rate was $50 \mathrm{mV} \mathrm{s}^{-1}$.

placed on the chip. A gradual increase in reaction current at $0.7 \mathrm{~V}$ was observed, as shown in Figure 8. But the increase was less than $0.01 \mu \mathrm{A}$ at the five-minute position. The error bar was calculated from the standard deviation value $(n=3)$. Considering that the measurement was conducted within one minute of sample addition, the crosstalk effect due to $\mathrm{H}_{2} \mathrm{O}_{2}$ diffusion was negligibly small in this experiment. The interference at site $\mathrm{B}$ from $\mathrm{H}_{2} \mathrm{O}_{2}$ generated at site $\mathrm{A}$ was also negligible because of the same mechanism. Sites A and B were $1.4 \mathrm{~mm}$ apart. This experiment confirmed selective detection of L-lactate and glucose; the measurement of interference behavior will aid in the design of other integrated sensing systems.
4.3. Calibration Curve Evaluation. CV curves were measured using various concentrations of L-lactate and glucose in PBS. Figures 9 and 10 show the dependence of the shape of the curve on the concentration of L-lactate and glucose, respectively. At the LOD-modified WE, the reaction current increased when the L-lactate concentration increased. At the GOD-modified WE, the reaction current increased when the glucose concentration increased. Anodic currents at a potential of $0.7 \mathrm{~V}$ were used to create calibration plots of L-lactate and glucose (Figure 11 and Figure 12, resp.). The dynamic ranges were about $0.2-1.0 \mathrm{mM}$ in L-lactate and $2.0-8.0 \mathrm{mM}$ in glucose. The sensitivities were $65 \mathrm{nA} /$ $\mathrm{mM}$ and $15 \mathrm{nA} / \mathrm{mM}$, respectively using WE of $0.5 \mathrm{~mm}^{2}$. 


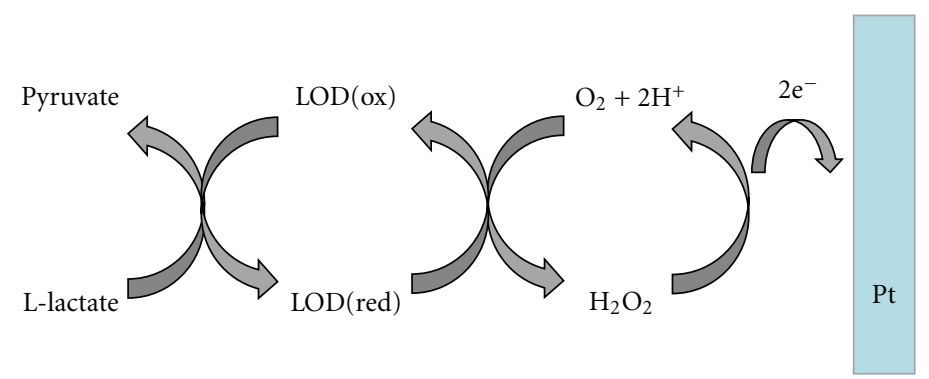

(a)

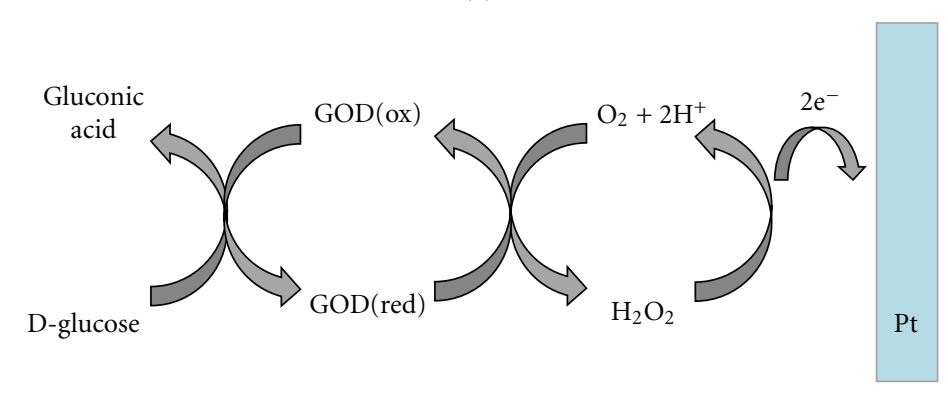

(b)

FIGURE 7: Electron-transfer mechanism of (a) L-lactate and (b) glucose sensing.

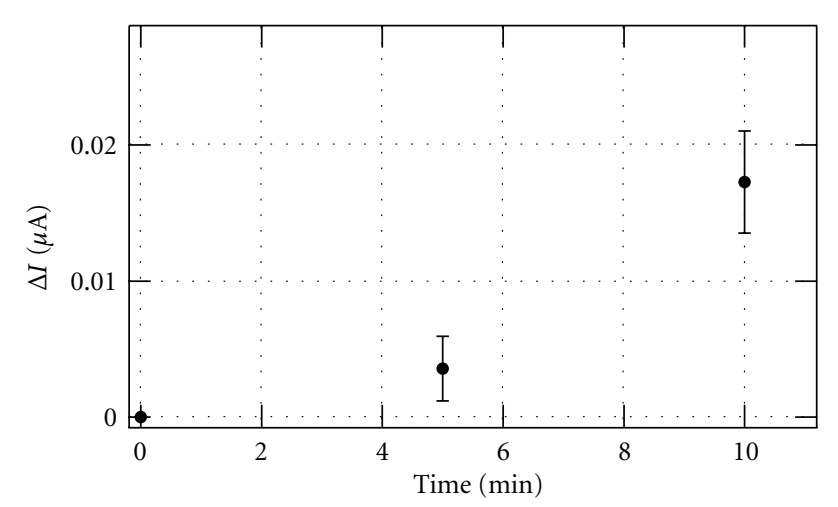

FIGURE 8: Crosstalk behavior: temporal measurement of reaction current at $0.7 \mathrm{~V}$ on site A while site $\mathrm{B}$ is active.

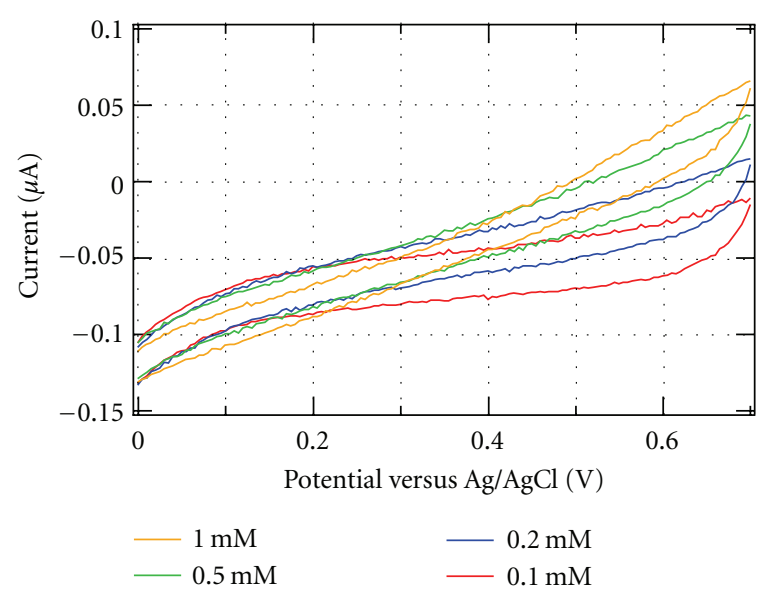

FIGURE 9: Cyclic voltammetry with various L-lactate concentrations. Scan rate was $50 \mathrm{mV} \mathrm{s}^{-1}$.

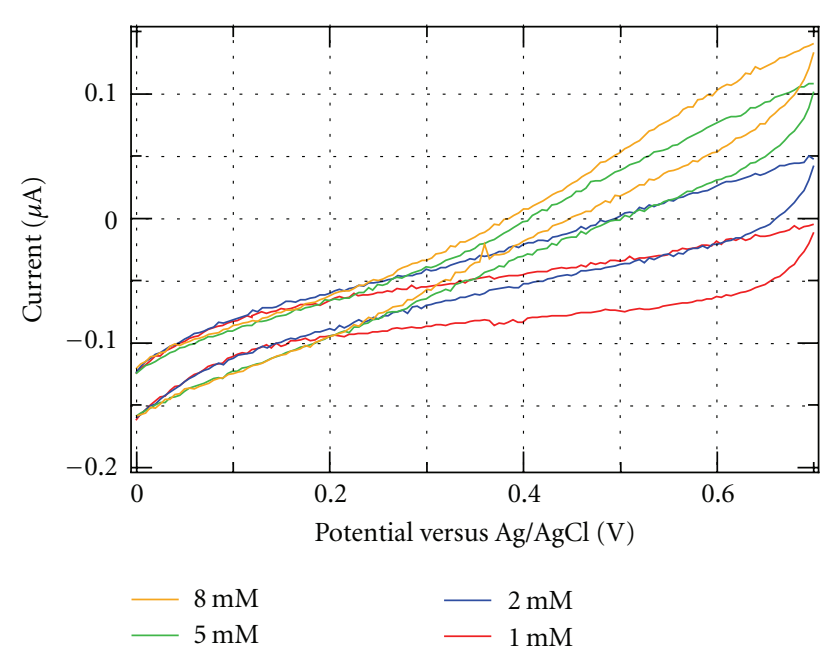

FIGURE 10: Cyclic voltammetry with various glucose concentrations. Scan rate was $50 \mathrm{mV} \mathrm{s}^{-1}$.

The $3 \sigma$ detection limit was $0.19 \mathrm{mM}$ and $1.1 \mathrm{mM}$, respectively.

\section{Conclusions}

In this study, we have successfully designed and fabricated an electrochemical sensing system with electrodes and a potentiostat integrated on a single chip. Not only WEs but also RE was installed on the chip. After simple pretreatment, LOD and GOD were immobilized on the WEs separately using the polyion complex method to detect L-lactate and glucose selectively and quantitatively. The interference behavior between two sites of WE was also studied. To 


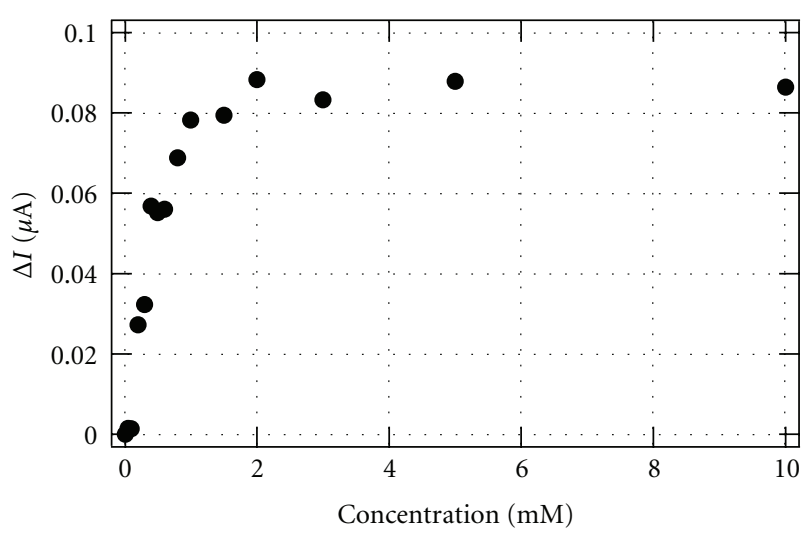

FIgURE 11: Calibration plot of L-lactate concentration at site A.

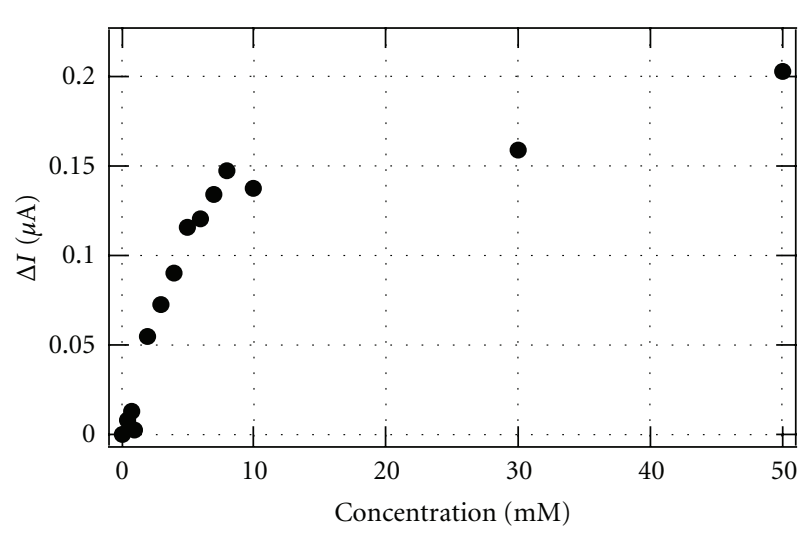

Figure 12: Calibration plot of glucose concentration at site B.

the best of our knowledge, this is the first chip on which multisite WEs, a CE, an RE, and signal-processing circuits are integrated onto a single chip. L-lactate and glucose were chosen to demonstrate the chip-shaped electrochemical sensing system. The concentrations of L-lactate and glucose were measured selectively at their respective sites. The measured dynamic ranges were $0.2-1.0 \mathrm{mM}$ for L-lactate and $2.0-8.0 \mathrm{mM}$ for glucose. The sensitivities were $65 \mathrm{nA} / \mathrm{mM}$ and $15 \mathrm{nA} / \mathrm{mM}$, respectively, using WE of $0.5 \mathrm{~mm}^{2}$, and the $3 \sigma$ detection limit was $0.19 \mathrm{mM}$ and $1.1 \mathrm{mM}$, respectively. Withthe integration of the standard CMOS process, this kind of chip could be the best candidate for realizing point-ofcare testing, including bedside diagnosis or on-site health checkups in the future.

\section{Acknowledgments}

The authors thank Professor Fumio Mizutani for information on the polyion complex method and Mr. Naoto Nakayama for helpful discussions. This work was supported in part by the Global COE Program "Frontiers of Intelligent Sensing" from the Ministry of Education, Culture, Sports, Science and Technology.

\section{References}

[1] N. G. Patel, A. Erlenkötter, K. Cammann, and G. C. Chemnitius, "Fabrication and characterization of disposable type lactate oxidase sensors for dairy products and clinical analysis," Sensors and Actuators, B, vol. 67, no. 1, pp. 134-141, 2000.

[2] A. Avramescu, T. Noguer, M. Avramescu, and J. L. Marty, "Screen-printed biosensors for the control of wine quality based on lactate and acetaldehyde determination," Analytica Chimica Acta, vol. 458, no. 1, pp. 203-213, 2002.

[3] J. Haccoun, B. Piro, V. Noël, and M. C. Pham, "The development of a reagentless lactate biosensor based on a novel conducting polymer," Bioelectrochemistry, vol. 68 , no. 2 , pp. 218-226, 2006.

[4] A. Parra, E. Casero, L. Vázquez, F. Pariente, and E. Lorenzo, "Design and characterization of a lactate biosensor based on immobilized lactate oxidase onto gold surfaces," Analytica Chimica Acta, vol. 555, no. 2, pp. 308-315, 2006.

[5] D. Pan, J. Chen, S. Yao, L. Nie, J. Xia, and W. Tao, "Amperometric glucose biosensor based on immobilization of glucose oxidase in electropolymerized o-aminophenol film at coppermodified gold electrode," Sensors and Actuators, B, vol. 104, no. 1, pp. 68-74, 2005.

[6] A. C. A. De Oliveira, V. C. Assis, M. A. C. Matos, and R. C. Matos, "Flow-injection system with glucose oxidase immobilized on a tubular reactor for determination of glucose in blood samples," Analytica Chimica Acta, vol. 535, no. 1-2, pp. 213-217, 2005.

[7] W. Z. Jia, K. Wang, and X. H. Xia, "Elimination of electrochemical interferences in glucose biosensors," TrAC-Trends in Analytical Chemistry, vol. 29, no. 4, pp. 306-318, 2010.

[8] H. Frebel, G. C. Chemnitius, K. Cammann, R. Kakerow, M. Rospert, and W. Mokwa, "Multianalyte sensor for the simultaneous determination of glucose, L-lactate and uric acid based on a microelectrode array," Sensors and Actuators, B, vol. 43, no. 1-3, pp. 87-93, 1997.

[9] R. Kurita, K. Hayashi, X. Fan, K. Yamamoto, T. Kato, and O. Niwa, "Microfluidic device integrated with pre-reactor and dual enzyme-modified microelectrodes for monitoring in vivo glucose and lactate," Sensors and Actuators, B, vol. 87, no. 2, pp. 296-303, 2002.

[10] S. Liu and Y. Sun, "Co-immobilization of glucose oxidase and hexokinase on silicate hybrid sol-gel membrane for glucose and ATP detections," Biosensors and Bioelectronics, vol. 22, no. 6, pp. 905-911, 2007.

[11] Y. Shi, H. Dou, A. Zhou, and Y. Chen, "Design and fabrication of a miniaturized electrochemical instrument and its preliminary evaluation," Sensors and Actuators, B, vol. 131, no. 2, pp. 516-524, 2008.

[12] M. Barbaro, A. Bonfiglio, L. Raffo, A. Alessandrini, P. Facci, and I. Barák, "Fully electronic DNA hybridization detection by a standard CMOS biochip," Sensors and Actuators, B, vol. 118, no. 1-2, pp. 41-46, 2006.

[13] Y. T. Cheng, C. Y. Tsai, and P. H. Chen, "Development of an integrated CMOS DNA detection biochip," Sensors and Actuators, B, vol. 120, no. 2, pp. 758-765, 2007.

[14] T. Tokuda, K. Tanaka, M. Matsuo, K. Kagawa, M. Nunoshita, and J. Ohta, "Optical and electrochemical dual-image CMOS sensor for on-chip biomolecular sensing applications," Sensors and Actuators, A, vol. 135, no. 2, pp. 315-322, 2007.

[15] J. Baader, H. Klapproth, S. Bednar et al., "Polysaccharide microarrays with a CMOS based signal detection unit," Biosensors and Bioelectronics, vol. 26, no. 5, pp. 1839-1846, 2010. 
[16] P. M. Levine, P. Gong, R. Levicky, and K. L. Shepard, "Active CMOS sensor array for electrochemical biomolecular detection," IEEE Journal of Solid-State Circuits, vol. 43, no. 8, pp. 1859-1871, 2008.

[17] T. Yamazaki, T. Ikeda, Y. Kano, H. Takao, M. Ishida, and K. Sawada, "Design and fabrication of complementary metaloxide-semiconductor sensor chip for electrochemical measurement," Japanese Journal of Applied Physics, vol. 49, no. 4, Article ID 04DL11, 4 pages, 2010.

[18] L. M. Fischer, M. Tenje, A. R. Heiskanen et al., "Gold cleaning methods for electrochemical detection applications," Microelectronic Engineering, vol. 86, no. 4-6, pp. 1282-1285, 2009.

[19] S. Iijima, F. Mizutani, S. Yabuki, Y. Tanaka, M. Asai, and T. Katsura, "Ferrocene-attached L-lysine polymers as mediators for glucose-sensing electrodes," Analytica Chimica Acta, vol. 281, no. 3, pp. 483-487, 1993.

[20] F. Mizutani, S. Yabuki, and Y. Hirata, "Amperometric Llactate-sensing electrode based on a polyion complex layer containing lactate oxidase. Application to serum and milk samples," Analytica Chimica Acta, vol. 314, no. 3, pp. 233-239, 1995.

[21] F. Mizutani, Y. Sato, Y. Hirata, and S. Yabuki, "Amperometric L-lactate-sensing electrode using an enzyme ultra-thin layer produced through the Co-adsorption of poly-L-lysine and lactate oxidase onto mercaptoalkanoic acid-modified gold surface," Denki Kagaku (Electrochemistry), vol. 64, no. 12, pp. 1266-1268, 1996. 

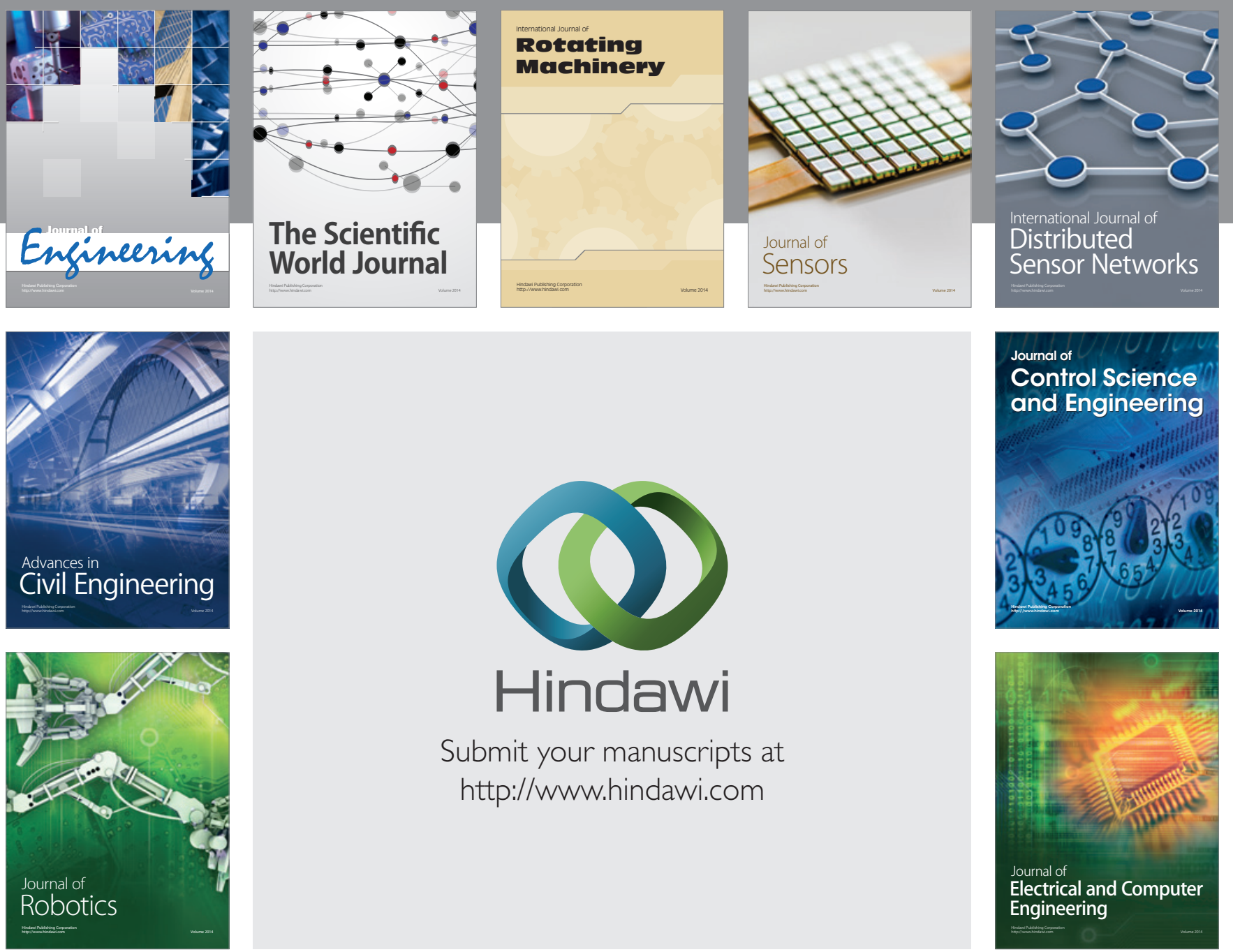

Submit your manuscripts at

http://www.hindawi.com
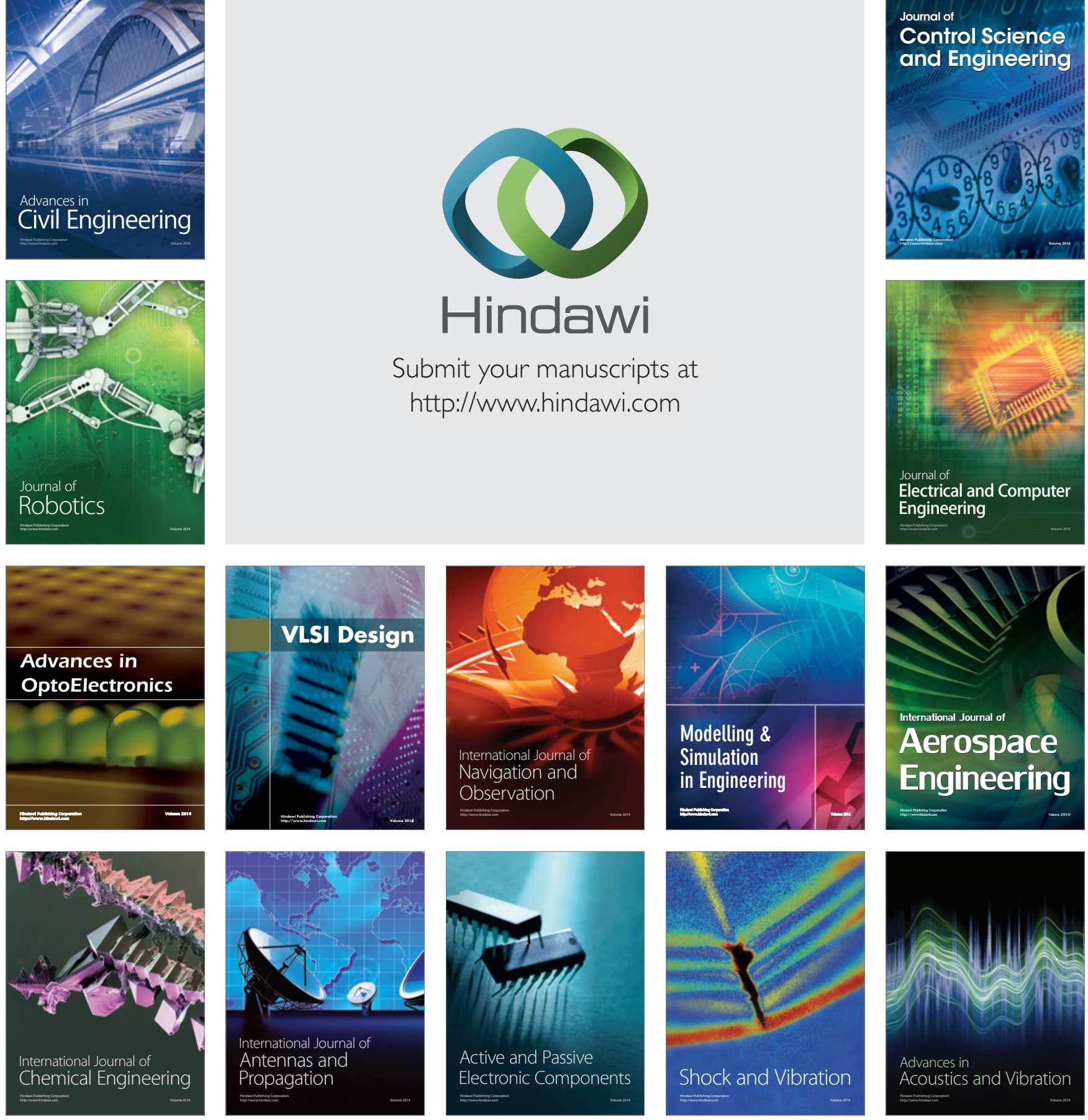